\title{
Nanoscale
}

(D) Check for updates

Cite this: Nanoscale, 2018, 10, 21425

\section{Switchable synchronisation of pirouetting motions in a redox-active [3]rotaxane $\uparrow$}

\author{
Hendrik V. Schröder, (iD a Amel Mekic,, Henrik Hupatz, ${ }^{a}$ Sebastian Sobottka, ${ }^{b}$ \\ Felix Witte, ${ }^{a}$ Leonhard H. Urner, ${ }^{a}$ Marius Gaedke, ${ }^{a}$ Kevin Pagel, ${ }^{a}, \mathrm{c}$ Biprajit Sarkar, (ID) b \\ Beate Paulus a and Christoph A. Schalley (iD *a
}

\begin{abstract}
In this study, the crown/ammonium [3] rotaxane R2 is reported which allows a switchable synchronisation of wheel pirouetting motions. The rotaxane is composed of a dumbbell-shaped axle molecule with two mechanically interlocked macrocycles which are decorated with a redox-active tetrathiafulvalene (TTF) unit. Electrochemical, spectroscopic, and electron paramagnetic resonance experiments reveal that rotaxane $\mathbf{R} \mathbf{2}$ can be reversibly switched between four stable oxidation states ( $\mathbf{R} 2, \mathbf{R} \mathbf{2}^{\cdot+}, \mathbf{R} \mathbf{2}^{2(\cdot+)}$, and $\mathbf{R} \mathbf{2}^{4+}$ ). The oxidations enable non-covalent, cofacial interactions between the TTF units in each state-including a stabilised mixed-valence $\left(\mathrm{TFF}_{2}\right)^{\cdot+}$ and a radical-cation $\left(\mathrm{TTF}^{\cdot+}\right)_{2}$ dimer interaction-which dictate a syn (R2, $\mathbf{R} \mathbf{2}^{\cdot+}$, and $\mathbf{R} \mathbf{2}^{2(\cdot+)}$ ) or anti $\left(\mathbf{R} \mathbf{2}^{4+}\right)$ ground state co-conformation of the wheels in the rotaxane. Furthermore, the strength of these wheel-wheel interactions varies with the oxidation state, and thus electrochemical switching allows a controllable synchronisation of the wheels' pirouetting motions. DFT calculations explore the potential energy surface of the counter-rotation of the two interacting wheels in all oxidation states. The controlled coupling of pirouetting motions in rotaxanes can lead to novel molecular gearing systems which transmit rotational motion by switchable non-covalent interactions.
\end{abstract}

Received 9th July 2018, Accepted 23rd October 2018

DOI: $10.1039 / \mathrm{c} 8 \mathrm{nr} 05534 \mathrm{c}$

rsc.li/nanoscale passive component to transmit rotational motion to the surrounding environment. ${ }^{5}$

Pioneering work on correlated rotational motion has been reported by Iwamura and Mislow who studied the dynamics of molecular bevel gears. ${ }^{6}$ These gears consist of covalently linked and tightly intermeshed triptycene groups. Based on the idea of sterically correlated rotors, the coupling of rotation has been further investigated in more sophisticated gearing systems. ${ }^{7}$ Moreover, it is desirable that molecular gears are also susceptible to external stimuli, and thus the transmission of rotational motion can be switched on and off or regulated in a controlled manner. ${ }^{8}$ Examples of molecular gears have been reported in which the steric rotor correlation can be influenced by ions, ${ }^{9}$ ligands, ${ }^{10}$ or light and thermal stimuli. ${ }^{11}$ Additionally, stimuli-controlled transmission of rotational motion has been achieved in gears based on organometallic carousel compounds such as metallocenes ${ }^{12}$ or double-decker porphyrins. ${ }^{13}$

The operation of such controllable gearing systems is reminiscent of the working principle of macroscopic clutches, common mechanical devices which can be found, for example, in motor vehicles. Transmission of rotation is realised by a connection between two rotating shafts. A disengagement (declutching) of the shafts leads to desynchronisation of rotation rates, and thus to an interruption of power transmission. Although the technomimetic comparison of mole- 


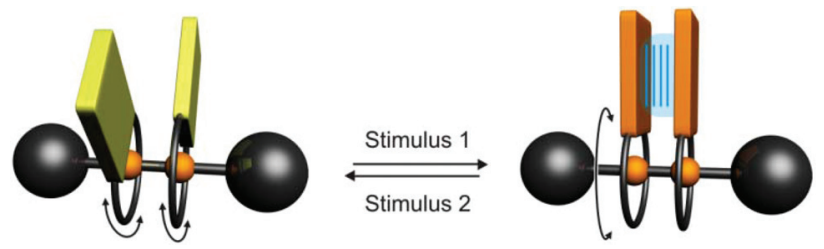

Fig. 1 Representation of a stimuli-responsive [3]rotaxane which allows a switchable synchronisation of macrocycle pirouetting motions.

cular machines at the nanoscale with macroscopic machines certainly has its limitations, ${ }^{14}$ this approach has been frequently used by groups in the field as it provides an easy-tounderstand description of the overall function of these molecular devices.

Here, we present a novel type of [3] rotaxane which allows the switchable synchronisation of pirouetting motions of two macrocycles (Fig. 1). Our molecular system is based on the symmetric [3] rotaxane R2 (Fig. 2). Two macrocycles are threaded on a dumbbell-shaped axle molecule. A synchronisation or, in other words, a coupling of the wheel's pirouetting motions can be achieved by switchable non-covalent interactions between the wheels. In this study, we show by a combination of experimental and theoretical methods two major outcomes: (i) $\mathbf{R} 2$ can be operated as a rotational switch in which the wheels adopt a syn or anti ground-state co-conformation. (ii) The wheel-wheel interactions, and thus the synchronisation of their pirouetting motions, can be adjusted by electrochemical switching.

\section{Results and discussion}

\section{Design considerations and synthesis}

In contrast to the well-studied wheel translation, for example in molecular shuttles, ${ }^{15}$ the use of the pirouetting motion in rotaxanes to drive a molecular machine remains challenging. ${ }^{1 b, 16}$ One reason is the high structural flexibility of most rotaxane architectures, which makes motion transmission by steric correlation difficult. However, a [3] rotaxane with two wheels is ideally suited to realise a coupling of wheel pirouetting motions. The wheels are spatially fixed in close contact by mechanical interlocking but can still freely rotate around the axle. The well-known crown/ammonium rotaxane motif was chosen due to its straightforward structural modifiability and high-yielding supramolecular synthesis. ${ }^{17}$ Stoddart and coworkers showed that axles with a trismethylene group between two ammonium binding sites provide a suitable spacing $\left(\begin{array}{ll}\sim 3.4 & \AA\end{array}\right)$ for $\pi-\pi$ interactions between crown ether macrocycles. ${ }^{18}$

The key building block in rotaxane $\mathbf{R} 2$ is the switching unit implemented in the wheels, which controls their non-covalent interactions. The organosulfur compound tetrathiafulvalene $e^{19}$ (TTF) is suitable, because TTF can undergo two reversible oneelectron oxidations to yield a stable radical-cation $\left(\mathrm{TTF}^{\circ+}\right)$ and dication $\left(\mathrm{TTF}^{2+}\right) .{ }^{20}$ Similar to viologen radical cations, ${ }^{21} \mathrm{TTF}$ radical cations have an outstanding ability to form longbonded dimers with cofacial arrangements: the mixed-valence dimer $\left(\mathrm{TTF}_{2}\right)^{\cdot+}$ and the radical-cation dimer $\left(\mathrm{TTF}^{\cdot+}\right)_{2} \cdot{ }^{22}$ These weakly-associated species are usually not stable in solution under ambient conditions. ${ }^{23}$ However, TTF dimers have been lately observed in carefully designed supramolecular complexes with confined environments including capsules, ${ }^{24}$ clips, ${ }^{25}$ or mechanically interlocked architectures such as rotaxanes $^{26}$ or catenanes. $^{27}$

In our previous work involving TTF-decorated crown/ ammonium (pseudo)rotaxanes, we directly implemented the TTF unit in a [24]crown-8 wheel (TTFC8). ${ }^{28}$ Coulomb repulsion between the oxidised wheel TTFC8 and the charged ammonium axles was used as the basis for redox-switchable shuttles. However, this design leads to the major drawbacks for the concept of synchronised wheel pirouetting: (i) the sulfur atoms in the wheel drastically lower the binding constant to dialkyl ammonium axles due to weaker hydrogen bonding. ${ }^{29}$ (ii) The spatial proximity of TTF and the axle causes charge repulsion between the oxidised TTF and the ammonium station. ${ }^{28 b}$ (iii) Unsubstituted TTF forms only weak dimers. To circumvent these difficulties, an extended

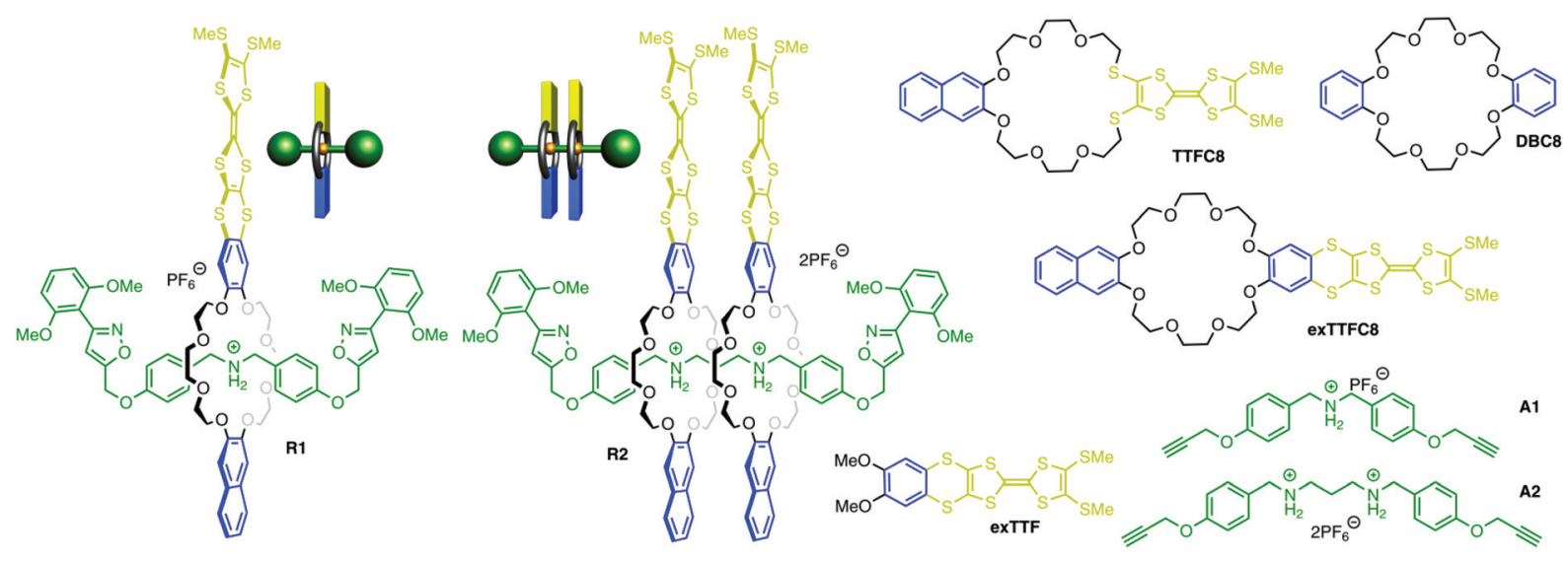

Fig. 2 Chemical structures of [3]rotaxane R2 and other compounds investigated in this report. 
macrocycle (exTTFC8) with a 1,2-dimercaptobenzene spacer between the TTF and the crown ether wheel was designed and synthesised (ESI, section 1.2†). In a very recent report, we showed that a TTF fused to a veratrole molecule (exTTF) features an enhanced dimer stability in comparison to unsubstituted $\mathrm{TTF}^{30}$

A prerequisite for efficient rotaxane capping synthesis is a sufficiently strong template effect in the pseudorotaxane precursor complexes. Isothermal titration calorimetry (ITC) with monovalent axle A1 and wheels exTTFC8, TTFC8 and dibenzo24-crown-8 (DBC8) showed mainly enthalpy-driven binding for all three pseudo[2] rotaxanes (ESI, section 4 and Table S1 $\dagger$ ). Compared to TTFC8 $\left(K_{\mathrm{a}}=(3.8 \pm 0.4) \times 10^{3} \mathrm{M}^{-1}\right.$ in $\mathrm{ClCH}_{2} \mathrm{CH}_{2} \mathrm{Cl} /$ $\mathrm{CH}_{3} \mathrm{CN}=10: 1$ ), a 13-fold increase of the binding constant is observed for exTTFC8 $\left(K_{\mathrm{a}}=(50 \pm 5) \times 10^{3} \mathrm{M}^{-1}\right)$. Furthermore, similar $\Delta H$ and $\Delta S$ values of exTTFC8 as compared to those of DBC8 corroborate our previous assumption of a stronger binding due to the separation of the crown binding site and TTF unit.

A capping strategy introduced by Takata and co-workers using a catalyst-free click reaction with a nitrile oxide stopper ${ }^{31}$ was employed for the synthesis of [3] rotaxane $\mathbf{R} 2$ (see section 1.3 in the ESI $\dagger$ for details). Besides the target compound R2, the structurally similar [2] rotaxane $\mathbf{R} 1$ bearing one wheel was synthesised. Since all intramolecular wheel-wheel interactions can be excluded, R1 serves as an ideal control compound to identify the effects in $\mathbf{R} 2$ that emerge from its divalent nature. Experimental evidence obtained by ${ }^{1} \mathrm{H},{ }^{13} \mathrm{C}$, and $2 \mathrm{D} \mathrm{NMR}$, high-resolution mass spectrometry, and infrared multiphoton dissociation experiments is consistent with the mechanically interlocked structures of both rotaxanes R1 and R2 (Fig. S1-7, ESI†).

\section{Electrochemical switching}

Two major questions arise for the switching of [3] rotaxane R2: (i) what is the wheels' ground state co-conformation (GSCC) in each oxidation state (Fig. 3a)? (ii) How strong are the TTF- induced wheel-wheel interactions, and thus the coupling between the wheels in each state (Fig. 3b)?

Regarding the first question, both macrocycles can pirouette around the axle and many different rotamers are potentially accessible. Only in a syn or anti co-conformation of the wheels, however, favorable cofacial stacking between the TTF and/or the naphthalene units is possible. ${ }^{32}$ Spectroscopic evidence for intramolecular TTF dimer interactions-for example mixed-valence or radical-cation interactions-would thus imply a syn GSCC of the wheels.

Initially, the electrochemical properties of rotaxanes $\mathbf{R} \mathbf{1}$ and R2 were probed by cyclic voltammetry (CV) experiments in $\mathrm{CH}_{3} \mathrm{CN}$ (Fig. 4). [2] Rotaxane $\mathbf{R} 1$ shows two reversible one-electron oxidations with half-wave potentials of $E_{1 / 2}^{1}=0.16 \mathrm{~V}$ and

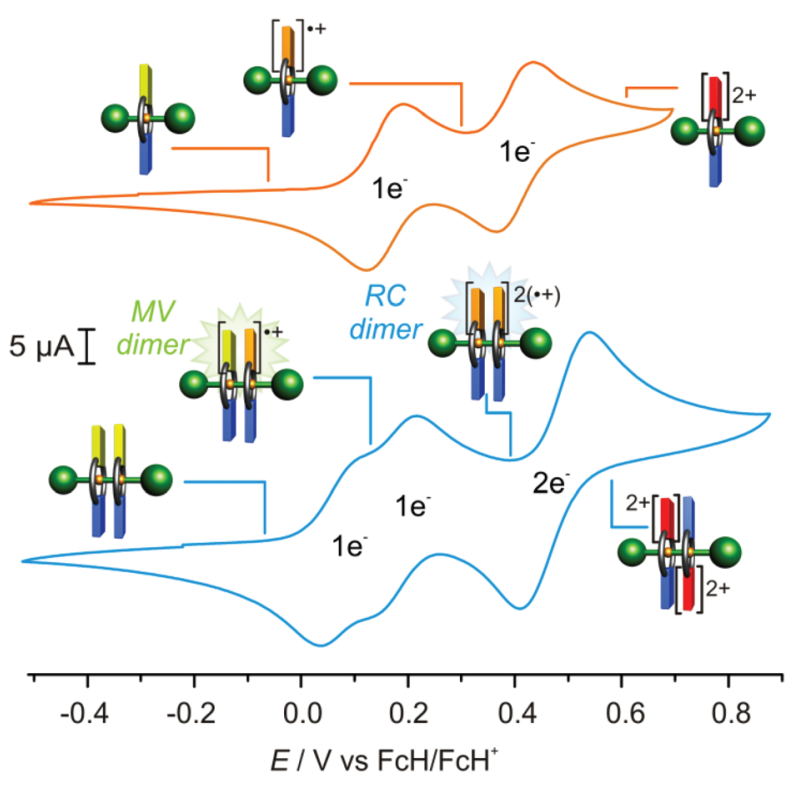

Fig. 4 Cyclic voltammograms $\left(\mathrm{CH}_{3} \mathrm{CN}, 298 \mathrm{~K}, 1.0 \mathrm{mM}, 100 \mathrm{mV} \mathrm{s}^{-1}\right)$ of rotaxanes $\mathbf{R} 1$ (orange) and $\mathbf{R} 2$ (blue) with $n-\mathrm{Bu}_{4} \mathrm{NPF}_{6}(0.1 \mathrm{M})$ as the electrolyte. (a)

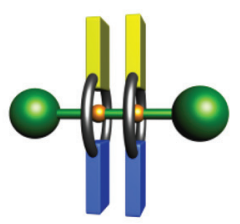

syn

(b)

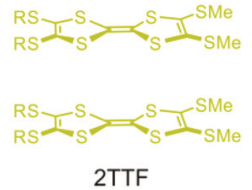

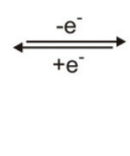

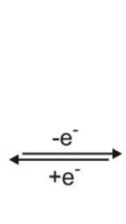

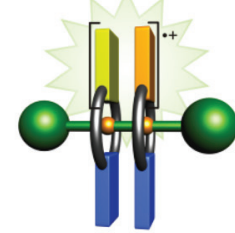

syn

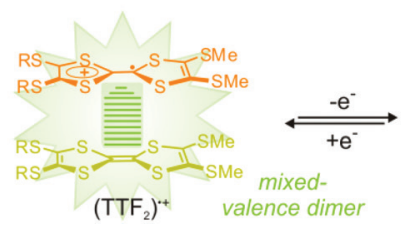

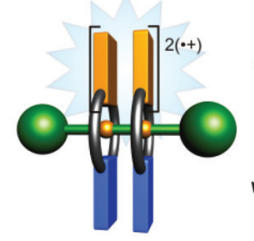

syn

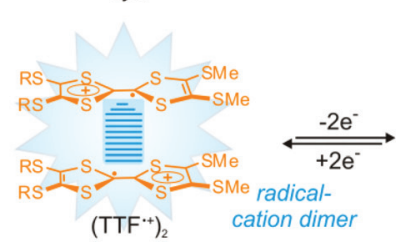

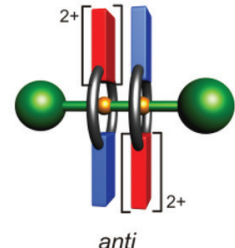

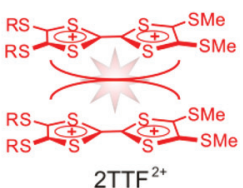

Fig. 3 (a) Graphical illustrations of [3]rotaxane R2 in all oxidation states to illustrate the expected interconversion between the syn and anti ground state co-conformations of the wheels. (b) Cofacial TTF-TTF dimer interactions during successive oxidation of the two TTF molecules in R2. 
$E_{1 / 2}^{2}=0.40 \mathrm{~V}$ against the ferrocene/ferrocenium couple which we assign to the two oxidations of the TTF unit. The potentials are very similar to those of monomer exTTF $(0.16$ and 0.39 V). ${ }^{30}$ This demonstrates that the positively charged ammonium axle has only a negligible effect on the TTF oxidation in R1. Additionally, no significant peak potential differences were observed for measurements of R1 and exTTFC8 in $\mathrm{CH}_{2} \mathrm{Cl}_{2}$ as a solvent of low dielectric constant (ESI, Fig. S12†). Thus, the charge-charge distance increase caused by the 1,2-dimercaptobenzene spacer sufficiently decreases the Coulomb repulsion between the oxidised TTF and charged axle.

[3]Rotaxane R2 shows characteristic differences as compared to its monovalent analogue R1: three reversible oxidation processes are observed, two one-electron and a two-electron process with half-wave potentials of $E_{1 / 2}^{1}=0.08 \mathrm{~V}, E_{1 / 2}^{2}=$ $0.19 \mathrm{~V}$, and $E_{1 / 2}^{3}=0.48 \mathrm{~V}$, respectively. The splitting of the first oxidation into two one-electron waves is indicative of an intramolecular mixed-valence interaction $\left(\left(\mathrm{TTF}_{2}\right)^{\circ+}\right){ }^{33}$ Based on the peak-to-peak separation, the comproportionation equilibrium of $\mathbf{R} 2^{\cdot+}$ can be determined $\left(K_{\mathrm{c}}=73\right)$ which clearly indicates a thermodynamically stable $\mathbf{R} 2{ }^{\cdot+}$ state. $^{33 a, 34}$ The third wave, corresponding to the $\mathbf{R} 2^{2(\cdot+)} \rightarrow \mathbf{R} 2^{4+}$ transition, is anodically shifted $(+0.08 \mathrm{~V})$ in contrast to the $\mathbf{R} \mathbf{1}^{{ }^{+}} \rightarrow \mathbf{R} \mathbf{1}^{2+}$ oxidation. This potential difference cannot merely be attributed to charge repulsion, as the system is flexible enough to elude the repulsion between the $\mathrm{TTF}^{2+}$ units by wheel pirouetting. ${ }^{33 c}$ Hence, the shift is assumed to be a consequence of an intramolecular stabilising interaction in the $\mathbf{R 2}^{2(\cdot+)}$ state, most likely the radical-cation dimer $\left(\mathrm{TTF}^{*+}\right)_{2}$, which has to be overcome by the additional potential.

In order to gain more detailed insight here, the CV data of R2 were evaluated by electrochemical digital simulations (DS), a powerful tool to establish chemical-electrochemical mechanisms and to estimate the thermodynamic and kinetic parameters of equilibrium reactions (ESI, section $5 \dagger$ ). ${ }^{35}$ Our simulations indicate the states $\mathbf{R 2}^{\cdot+}$ and $\mathbf{R 2}^{2(\cdot+)}$ to be significantly stabilised by attractive wheel-wheel interactions. The estimated stabilisation energies in the four different states provide the following wheel-wheel interaction ranking: $\mathbf{R 2}^{\mathbf{*}^{+}}$(mixedvalence dimer) $>\mathbf{R} \mathbf{2}^{2(\cdot+)}$ (radical-cation dimer) $>\mathbf{R} \mathbf{2} \gg \mathbf{R} \mathbf{2}^{4+}$. This follows the order of the previously reported dimerisation energies of TTF monomers. ${ }^{22,30}$ Notably, $\mathbf{R} 2^{4+}$ displays a significantly smaller attractive interaction than neutral $\mathbf{R} 2$ implying that the repulsive forces between the wheels affect the $\mathbf{R 2}^{4+}$ state. Here, charge repulsion between the two $\mathrm{TTF}^{2+}$ units leads to an opening of the cofacial TTF dimer and subsequently to a change in the wheel's co-conformation. ${ }^{27,33 b}$ An anti GSCC is reasonable as it increases the charge-charge distance and simultaneously enables cofacial interactions between the electronpoor $\mathrm{TTF}^{2+}$ and the electron-rich naphthalene units.

The paramagnetic properties of $\mathbf{R} 1$ and $\mathbf{R} 2$ in their different oxidation states were investigated by continuous wave electron paramagnetic resonance (CW EPR) titration experiments (Fig. 5a). $\mathrm{CH}_{3} \mathrm{CN}$ solutions of $\mathbf{R} 1$ and $\mathbf{R} 2$ were chemically oxidised by stepwise addition of $\mathrm{Fe}\left(\mathrm{ClO}_{4}\right)_{3}$ as a one-electron oxidant. A test reaction using $\mathrm{Zn}$ dust for back reduction (a)
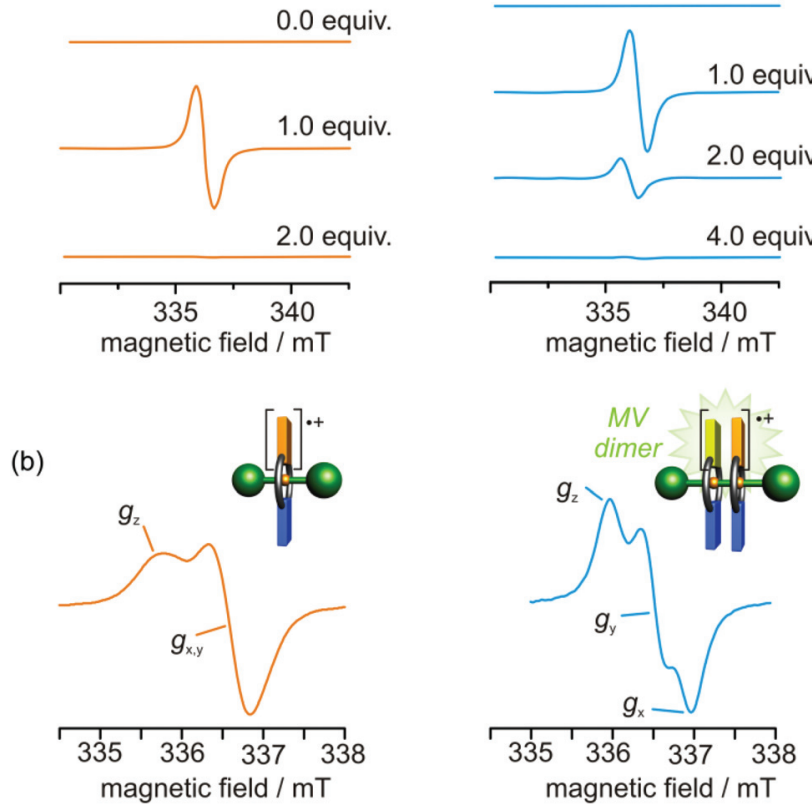

Fig. 5 (a) CW EPR spectra $\left(\mathrm{CH}_{3} \mathrm{CN}, 298 \mathrm{~K}, 0.1 \mathrm{mM}\right)$ of [2]rotaxane R1 (orange) and [3]rotaxane $\mathrm{R} 2$ (blue) upon titration with the oxidant $\mathrm{Fe}$ $\left(\mathrm{ClO}_{4}\right)_{3}$. (b) EPR spectra $(163 \mathrm{~K}, 0.1 \mathrm{mM})$ of frozen $\mathrm{CH}_{2} \mathrm{Cl}_{2}$ solutions of $\mathrm{R}^{\cdot+}$ and $\mathrm{R}^{\cdot+}$.

demonstrates the reversibility of this chemical oxidation (ESI, Fig. S9b $\dagger$ ). ${ }^{28 a, 30}$ After each addition of the oxidant, an EPR spectrum was recorded. For R1, addition of 1.0 equiv. of the oxidant leads to a signal with $g=2.010$ which corresponds to the radical-cationic species $\mathbf{R 1}{ }^{\cdot+} \cdot{ }^{23}$ Further oxidation results in a decrease of intensity in accordance with an $\mathbf{R 1}^{2+}$ singlet state. The same protocol was applied for [3]rotaxane R2. A maximum of intensity for the paramagnetic $\mathbf{R 2}^{++}$state $(g=$ 2.010 ) is reached after the addition of 1.0 equiv. of the oxidant. The signal intensity decreases with further oxidation which indicates radical-paring and is thus indicative of the formation of a diamagnetic radical-cation dimer $\left(\left(\mathrm{TTF}^{\circ+}\right)_{2}\right)$ in rotaxane $\mathbf{R 2}^{2(\cdot+)} \cdot \cdot^{22,27,36}$ However, a weak signal is still present after adding 2.0 equiv. which may be explained by charge disproportionation or equilibria between the EPR-silent radicalcation dimer and alternative EPR-active co-conformations of $\mathbf{R} 2^{2(+)} \cdot{ }^{27,37}$ Further oxidation leads to a virtual absence of any signal intensity which is, again, in accordance with the diamagnetic $\mathbf{R} 2^{4+}$ state.

In solution, molecular tumbling of paramagnetic molecules often averages out the anisotropy of the $g$-factor which gives a more detailed view on the coupling to the electrostatic field of the spatial environment. In frozen solution, however, the $g$ factor anisotropy can become visible. ${ }^{38}$ Therefore, additional EPR experiments of $\mathbf{R} 1^{\cdot+}$ and $\mathbf{R} 2{ }^{\cdot+}$ were performed in $\mathrm{CH}_{2} \mathrm{Cl}_{2}$ at room temperature and in frozen solutions (Fig. 5b). The radical species were prepared by prior chemical oxidation with $\mathrm{Fe}\left(\mathrm{ClO}_{4}\right)_{3}$. At room temperature, rotaxanes $\mathbf{R 1}^{\cdot+}$ and $\mathbf{R} 2^{\cdot+}$ show isotropic signals at $g$ values of 2.009 and 2.008 , respectively. In 
frozen solution $(163 \mathrm{~K})$, however, $\mathbf{R 1}^{\cdot+}$ exhibits $g$-anisotropy and shows an EPR spectrum of axial symmetry with $g$-values $g_{z}$ $=2.012$ and $g_{x, y}=2.008$. Going from $\mathbf{R} 1^{{ }^{+}}$to $\mathbf{R} 2^{{ }^{+}}$, an EPR spectrum of rhombic symmetry with three $g$-values of 2.011, 2.008 and 2.005 is observed. This indicates that the radical in $\mathbf{R} 2^{-+}$ experiences environmental effects different from those in $\mathbf{R 1}^{\mathbf{}}$ in agreement with the mixed-valence interaction in $\mathbf{R}{ }^{\cdot+}$.

The presence of a radical-cation dimer in $\mathbf{R} 2^{2(\cdot+)}$ was further verified by UV/Vis-NIR spectroscopy in $\mathrm{CH}_{3} \mathrm{CN}$. Fig. 6a depicts the photometric titrations of rotaxanes $\mathbf{R} \mathbf{1}$ and $\mathbf{R} 2$ by the oxidant $\mathrm{Fe}\left(\mathrm{ClO}_{4}\right)_{3}$. After the addition of 1.0 equiv. of oxidant, $\mathbf{R 2}^{\cdot+}$ displays characteristic $\mathrm{TTF}^{{ }^{*+}}$ bands $(450,870 \mathrm{~nm})$ accompanied by a broad low intensity charge-resonance band $(>1300 \mathrm{~nm})$ of the mixed-valence dimer $\left(\mathrm{TTF}_{2}\right)^{\cdot+} \cdot{ }^{30,37,39}$ The low-energy band disappears in the course of further oxidation. The addition of 2.0 equiv. results in the formation of the radical-cation dimer interaction $\left(\left(\mathrm{TTF}^{\bullet+}\right)_{2}\right)$ as clearly seen from the emergent shoulder ${ }^{33 c}$ between 1000 and $1500 \mathrm{~nm}$ and the blue shift (ESI, Fig. S9a†) of the $\mathrm{TTF}^{\cdot+}$ bands at $430 \mathrm{~nm}$ and $820 \mathrm{~nm}$. This Davydov blue shift is diagnostic of cofacially stacked radical-cation dimers ${ }^{40}$ and is not observed in the oxidation of R1. This is an additional strong piece of evidence for a syn GSCC in $\mathbf{R} 2^{2(\cdot+)}$. A typical $\mathrm{TTF}^{2+}$ band at $660 \mathrm{~nm}$ is observed for the fully oxidised rotaxane $\mathbf{R} 2^{4+}$. The differences in absorption for each state can also be easily identified with the naked eye (Fig. 6b). Including the sextuply (including the two ammonium ions of the axle) charged $\mathbf{R} 2^{4+}$ state, all chemically generated oxidation states of $\mathbf{R 2}$ showed remarkable stability in $\mathrm{CH}_{3} \mathrm{CN}$ towards moisture and air for several months as indicated by the persistent colors of the solutions.

\section{Co-conformation of non-switched R2}

To reveal the co-conformation and wheel-wheel interactions of R2 before electrochemical switching, further ITC investigations of the pseudo[3]rotaxane formation with divalent axle $\mathbf{A} 2$ and
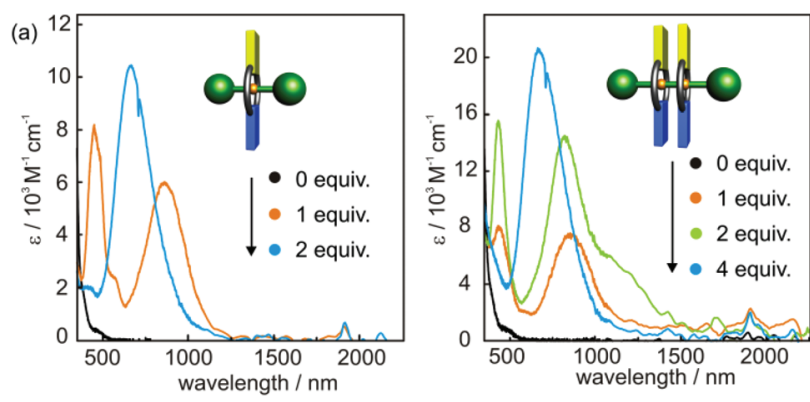

(b)

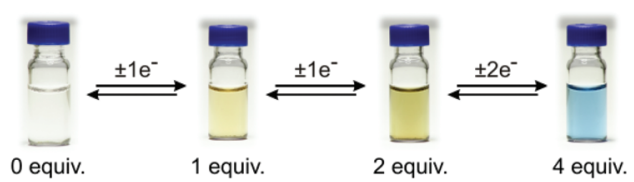

Fig. 6 (a) UV/Vis-NIR spectra $\left(\mathrm{CH}_{3} \mathrm{CN}, 298 \mathrm{~K}, 2.5 \times 10^{-5} \mathrm{M}\right)$ of rotaxanes R1 (left) and R2 (right) upon titration with the oxidant $\mathrm{Fe}\left(\mathrm{ClO}_{4}\right)_{3}$. (b) Photographs of $\mathrm{R} 2$ solutions $\left(\mathrm{CH}_{3} \mathrm{CN}, 10^{-4} \mathrm{M}\right)$ in all four stable oxidation states.
exTTFC8 were conducted and compared with the binding data obtained for the TTF-free control A2 $\subset(\text { DBC8) })_{2}$ (ESI, section 4 and Table S1 $\dagger$ ). Not unexpectedly, $\mathbf{A 2 \subset ( D B C 8 ) _ { 2 }}$ displays similar binding enthalpies for both wheels $\left(\Delta H_{1}=(-35.6 \pm 1.3) \mathrm{kJ}\right.$ $\left.\mathrm{mol}^{-1} ; \Delta H_{2}=(-31.1 \pm 4.9) \mathrm{kJ} \mathrm{mol}^{-1}\right)$. Consequently, non-cooperative binding occurs here. In marked contrast, the second crown ether in $\mathbf{A} 2 \subset(\mathbf{e x T T F C 8})_{2}$ binds significantly stronger than the first $\left(\Delta H_{1}=(-32.6 \pm 1.0) \mathrm{kJ} \mathrm{mol}^{-1} ; \Delta H_{2}=(-45.4 \pm\right.$ 4.3) $\mathrm{kJ} \mathrm{mol}^{-1}$ ). This clearly points to positive cooperativity, which can easily be traced back to the attractive $\pi$-interactions between the two cofacial exTTFC8 wheels. The TTF and naphthalene units are thus crucial for the wheel-wheel interactions in A2 $\subset(\text { exTTFC8 })_{2} \cdot{ }^{41}$ However, the more fixed conformation leads to a strong entropic penalty of the second binding event which decreases $K_{2}$ in comparison with $K_{1}$. In accordance with the ITC results, the ${ }^{1} \mathrm{H}$ NMR spectrum of $\mathbf{R} 2$ shows significant high-field shifts of the wheels' naphthalene signals $(\Delta \delta=-0.24 \mathrm{ppm})$ in comparison with R1 (Fig. S8, ESI $\dagger$ ). We attribute these shifts to a shielding effect caused by the intramolecular $\pi$-interactions between the two wheels in R2. ${ }^{18 b}$

Since no crystals suitable for X-ray diffraction could be obtained, ion mobility mass spectrometry (IM-MS) was applied to investigate the conformation and underpin the assumption of a syn GSCC of the wheels in the R2 state (see section 6 and Table $\mathrm{S} 2$ in the $\mathrm{ESI} \dagger$ for details). IM-MS has proven to be highly valuable to unravel the conformations of mechanically interlocked molecules. ${ }^{18 a, 28 c, 42}$ The mass spectrum obtained from $\mathbf{R} 2$ shows one signal $(m / z=1217)$ that corresponds to the $\left[\mathbf{R} 2-2 \mathrm{PF}_{6}\right]^{2+}$ ion (Fig. S15a, ESI $\dagger$ ). IM-MS analysis revealed only one narrow and Gaussian-shaped arrival time distribution for the $\left[\mathbf{R} 2-2 \mathrm{PF}_{6}\right]^{2+}$ ion indicating the presence of one energetically preferred conformer (ESI, Fig. S15b †). The experimental collision cross section (CCS) of $410 \AA^{2}$ matches with the theoretical CCS calculated from a force-field-optimised structure in which the wheels adopt a syn GSCC (412 $\left.\mathrm{A}^{2}\right)$. Theoretical CCS values calculated for other possible wheel coconformations were instead not consistent with the experimental CCS, which underlines the assumption that the syn GSCC is the most relevant conformation (ESI, Table S2 $\dagger$ ). Although the structure of $\mathbf{R} 2$ in the gas phase is not necessarily identical to that in solution, such a syn GSCC is in good agreement with the ITC data and NMR results.

\section{DFT calculations}

Theoretical calculations were employed to gain further insight into the energetics and conformational aspects of R2. After structural relaxation of each co-conformation (syn and anti) in each of its four charge states, i.e. 8 structures in total, single point calculations at the PBE0-D3(BJ)/def2-TZVP level of DFT were performed to estimate co-conformational stabilities and oxidation potentials (for full computational details, see the ESI $\dagger$ ). Additionally, the valence electronic structure of $\mathbf{R} 2$ is investigated. We have shown previously that this level of theory sufficiently describes the conformational and electronic properties of our redox-active compounds. ${ }^{30}$ Fig. 7 depicts the 
(a)
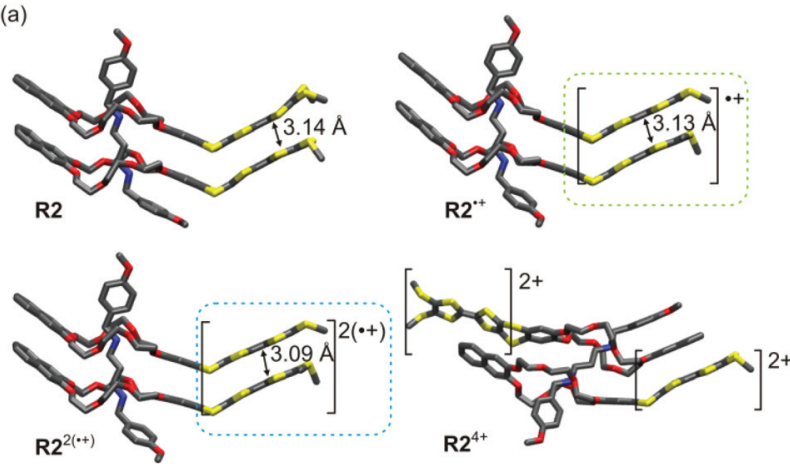

(b)
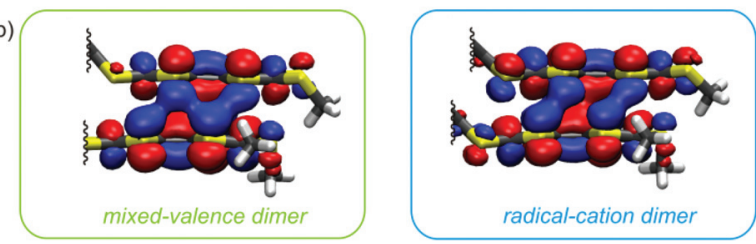

Fig. 7 (a) Calculated structures of the GSCC of a stopper-less pseudorotaxane analogue of R2 in its four oxidation states. (b) Bonding orbitals of the $T F_{2}$ complex in the mixed-valence and radical-cation dimer states.

most stable co-conformation of a computer-time-reducing, stopper-less pseudorotaxane analogue of $\mathbf{R} 2$ in each state. In agreement with the experimental findings, the calculations suggest a syn GSCC for $\mathbf{R} 2, \mathbf{R} 2^{\cdot+}$, and $\mathbf{R} 2^{2\left(\bullet^{+}\right)}$whereas the anti co-conformation is lower in energy for $\mathbf{R} 2^{4+}$. This is further supported by structural changes: during the first two oxidation processes in syn-R2, the interplanar distance between the TTF units decreases from $3.14 \AA$ to $3.09 \AA$ while the distance between the stacked naphthalene moieties remains rather constant around $3.32 \AA$. However, the last oxidation results in a significant increase of the TTF-TTF distance (from $3.09 \AA$ to $3.17 \AA$ ) and a notable decrease of the naphthalene dimer separation (from $3.32 \AA$ to $3.16 \AA$ ) due to the unfavourable electrostatic interaction of the two $\mathrm{TTF}^{2+}$ units. In contrast to syn-R2, the interplanar distances in anti-R2 are only slightly altered upon oxidation (going from $3.31 \AA$ in anti-R2 to $3.27 \AA$ in anti$\mathbf{R 2}{ }^{4+}$.

Analysis of the molecular orbitals reveals that the valence electronic structure of $\mathbf{R} 2^{\cdot+}$ and $\mathbf{R} 2^{2(\cdot+)}$ is dominated by the mixed-valence and radical-cation dimer interactions, respectively, as visualised in Fig. 7b. The shape of the valence orbitals suggests multi-centered bonding ${ }^{43}$ between the TTF units leading to attractive non-covalent interactions. Computed energies for the oxidative processes decently agree with experimental trends (Table S3, ESI†). Two contributions were considered: the pure electronic energy difference between two oxidation states and the difference arising from the rearrangement of a syn to an anti co-conformation or vice versa. For the second oxidative transition $\left(\mathbf{R} 2^{\cdot+} / \mathbf{R} 2^{2(\cdot+)}\right)$ no rearrangement is expected and, hence, the mere electronic contribution reproduces the experiment very well. (a)

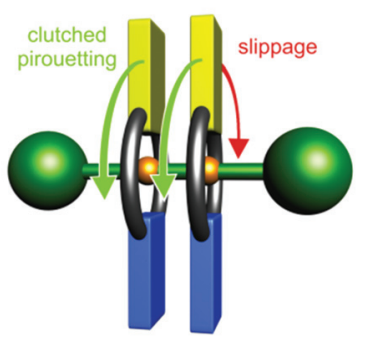

(b)

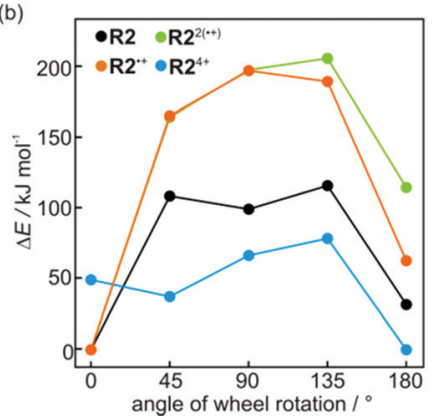

Fig. 8 (a) Schematic representation of the two rotational wheel motions in R2 relative to the axle molecule. (b) DFT results of relaxed angular PES scans for counter-rotation of the wheels (slippage) in all stable oxidation states of R2.

\section{Rotational motions}

As illustrated in Fig. 8a, two rotational motions can be assumed for the wheels of R2: (i) a concerted pirouetting of the clutched macrocycles around the dialkyl ammonium thread (green arrow) or (ii) an independent counter-rotation of both wheels reminiscent of a slippage motion (red arrow).

The degree of concertedness of the wheel pirouetting increases with the strength of attractive wheel-wheel interactions in the different oxidation states as the most relevant parameter. However, in order to draw conclusions about the rotation from the interaction energies-that are thermodynamic values - it is necessary to know that there are no other barriers hampering the rotation of the wheels around the axle. In other words, only when the crown ethers are generally free to rotate, the TTF/TTF or TTF/naphthalene interactions will determine how much concerted, clutched motion occurs and how important gear slippage becomes.

Variable-temperature NMR (VT-NMR) experiments with R2 result in only one set of signals for a $C_{2 \mathrm{v}}$ symmetric species indicating a fast rotamer interconversion at room temperature. Upon gradual cooling to $203 \mathrm{~K}(400 \mathrm{MHz})$, the ${ }^{1} \mathrm{H}$ signals strongly broaden, but no decoalescence was observed. This is in accordance with other crown ether complexes, which show fast rotation with low barriers that is not detectable by standard VT-NMR techniques. ${ }^{44}$ Consequently, the wheels in $\mathbf{R} 2$ undergo a fast and random pirouetting motion even at temperatures significantly lower than room temperature. Unfortunately, the presence of paramagnetic species in the $\mathbf{R} 2^{\cdot+}, \mathbf{R} 2^{2(\cdot+)}$, and $\mathbf{R} 2^{4^{+}}$ states prevents reliable VT-NMR measurements for these states. Nevertheless, it is reasonable to assume that the rotation of the wheels is still fast in these states.

Quantum mechanical methods are a commonly-used tool ${ }^{7}$ to approach the potential energy surface (PES) of molecular gears and rotors and to calculate energy barriers for different motions. Restricted optimisations and subsequent single-point calculations at the PBE0 level were performed for $\mathbf{R} 2$ in steps of $45^{\circ}$ for the dihedral angle between the two TTF units (Fig. S18, $\mathrm{ESI} \dagger$ ). Estimated barriers for counter-rotation of the wheels were obtained which are in the order of $c a .200 \mathrm{~kJ} \mathrm{~mol}^{-1}$ for $\mathbf{R}{ }^{\cdot+}$ and 
$\mathbf{R} 2^{2(\cdot+)}$ (Fig. $8 \mathrm{~b}$ ). These two oxidation states are thus much more strongly clutched in their syn co-conformation in comparison to $\mathbf{R 2}$ and $\mathbf{R 2}^{4+}$, for which these barriers are notably lower in energy. While non-switched $\mathbf{R} 2$ shows a medium barrier height of approximately $100 \mathrm{~kJ} \mathrm{~mol}^{-1}$, syn- $\mathbf{R 2}^{4+}$ is not even predicted to be a local minimum structure. The latter readily falls into an intermediate structure at around $45^{\circ}$ which in turn converts into the anti co-conformation with a barrier of $\sim 40 \mathrm{~kJ} \mathrm{~mol}^{-1}$. This can be attributed to the increasing Coulomb repulsion between the $\mathrm{TTF}^{2+}$ units. A clear differentiation between $\mathbf{R 2}^{\cdot+}$ and $\mathbf{R} 2^{2(\cdot+)}$ is rather difficult as their rotational motion is governed by a similar degree of non-covalent interactions. Although absolute values for rotational barriers may suffer from errors inherent in the applied DFT approach, their relative trends should be reliable. In spite of this, the calculations clearly indicate that a co-conformational change is accomplished in the last oxidative process when going from $\mathbf{R}^{2(\cdot+)}$ to $\mathbf{R 2}^{4+}$, which is in agreement with our experimental findings.

Overall, the experimental and computational results indicate stronger wheel-wheel interactions-and, thus, a higher barrier of wheel slippage-for the $\mathbf{R} 2^{\cdot+}$ and $\mathbf{R} 2^{2(\cdot+)}$ states than for the $\mathbf{R} 2$ and $\mathbf{R} 2^{4+}$ states. This clearly confirms the function as a switchable system with different motion coupling efficiencies in the four oxidation states. Although the wheels of the [3] rotaxane cannot be fully disengaged, the coupling can be adjusted by electrochemical switching.

\section{Conclusions}

In summary, the synthesis and electrochemical switching of a crown/ammonium [3] rotaxane R2 consisting of a dumbbellshaped axle with two tetrathiafulvalene-decorated wheels has been reported. The rotaxane can be switched between four stable oxidation states including two states featuring mixedvalence $\left(\mathrm{TTF}_{2}\right)^{\circ+}$ or radical-cation $\left(\mathrm{TTF}^{\circ+}\right)_{2}$ dimer interactions. Each state shows a specific wheel ground state co-conformation and wheel-wheel interactions of different strengths. Quantum chemical calculations reveal that the barrier for gear slippage, which is identical to the counter-rotation of both wheels, can be adjusted by electrochemical switching. To the best of our knowledge, this is the first example of a gear-type system which operates with wheel pirouetting motions in a rotaxane. The switchable synchronisation of pirouetting motions equates with the working principle of a controllable gearing system. As a next step, ordered arrays of these rotaxanes on surfaces or in solid state materials could be investigated regarding their optoelectronic and conformational properties in external fields. A concerted behaviour of such multidimensional arrays may lead to macroscopic effects which are highly interesting for functional devices.

\section{Conflicts of interest}

There are no conflicts to declare.

\section{Acknowledgements}

This research was funded by the Deutsche Forschungsgemeinschaft (CRC 765). We thank Max Bartetzko and Mathias Ellwanger for NMR measurements, Fabian Klautzsch for help with the ITC, Jongcheol Seo for help with IM-MS, and Constantin Stuckhardt for help with synthesis.

\section{Notes and references}

1 (a) V. Balzani, A. Credi, F. M. Raymo and J. F. Stoddart, Angew. Chem., Int. Ed., 2000, 39, 3348; (b) S. Erbas-Cakmak, D. A. Leigh, C. T. McTernan and A. L. Nussbaumer, Chem. Rev., 2015, 115, 10081.

2 (a) D. Stock, Science, 1999, 286, 1700; (b) H. Terashima, S. Kojima and M. Homma, Int. Rev. Cell Mol. Biol., 2008, 270, 39.

3 S. Kassem, T. van Leeuwen, A. S. Lubbe, M. R. Wilson, B. L. Feringa and D. A. Leigh, Chem. Soc. Rev., 2017, 46, 2592.

4 N. Koumura, R. W. Zijlstra, R. A. van Delden, N. Harada and B. L. Feringa, Nature, 1999, 401, 152.

5 (a) P. Stacko, J. C. M. Kistemaker, T. van Leeuwen, M. C. Chang, E. Otten and B. L. Feringa, Science, 2017, 356, 964; (b) M. Baroncini and A. Credi, Science, 2017, 356, 906.

6 H. Iwamura and K. Mislow, Acc. Chem. Res., 1988, 21, 175.

7 G. S. Kottas, L. I. Clarke, D. Horinek and J. Michl, Chem. Rev., 2005, 105, 1281.

8 (a) W. R. Browne and B. L. Feringa, Nat. Nanotechnol., 2006, 1, 25; (b) B. L. Feringa, Angew. Chem., Int. Ed., 2017, 56, 11060.

9 W. Setaka, T. Nirengi, C. Kabuto and M. Kira, J. Am. Chem. Soc., 2008, 130, 15762.

10 K. Sanada, H. Ube and M. Shionoya, J. Am. Chem. Soc., 2016, 138, 2945.

$11 \mathrm{H}$. Ube, Y. Yasuda, H. Sato and M. Shionoya, Nat. Commun., 2017, 8, 14296.

12 (a) J. D. Crowley, I. M. Steele and B. Bosnich, Chem. - Eur. J., 2006, 12, 8935; (b) A. Iordache, M. Oltean, A. Milet, F. Thomas, B. Baptiste, E. Saint-Aman and C. Bucher, J. Am. Chem. Soc., 2012, 134, 2653.

13 S. Ogi, T. Ikeda, R. Wakabayashi, S. Shinkai and M. Takeuchi, Chem. - Eur. J., 2010, 16, 8285.

14 J. Schummer, Found. Chem., 2006, 8, 53.

15 (a) P. L. Anelli, N. Spencer and J. F. Stoddart, J. Am. Chem. Soc., 1991, 113, 5131; (b) A. Altieri, F. G. Gatti, E. R. Kay, D. A. Leigh, D. Martel, F. Paolucci, A. M. Slawin and J. K. Wong, J. Am. Chem. Soc., 2003, 125, 8644; (c) F. Coutrot and E. Busseron, Chem. - Eur. J., 2008, 14, 4784.

16 (a) E. A. Neal and S. M. Goldup, Chem. Commun., 2014, 50, 5128; (b) C. A. Schalley, K. Beizai and F. Vögtle, Acc. Chem. Res., 2001, 34, 465.

17 (a) P. R. Ashton, P. J. Campbell, P. T. Glink, D. Philp, N. Spencer, J. F. Stoddart, E. J. T. Chrystal, S. Menzer, D. J. Williams and P. A. Tasker, Angew. Chem., Int. Ed. Engl., 
1995, 34, 1865; (b) N. Yamaguchi and H. W. Gibson, Angew. Chem., Int. Ed., 1999, 38, 143; (c) T. J. Hubin and D. H. Busch, Coord. Chem. Rev., 2000, 200-202, 5; (d) X. Fu, Q. Zhang, S. J. Rao, D. H. Qu and H. Tian, Chem. Sci., 2016, 7, 1696; (e) S. J. Rao, Q. Zhang, J. Mei, X. H. Ye, C. Gao, Q. C. Wang, D. H. Qu and H. Tian, Chem. Sci., 2017, 8, 6777.

18 (a) M. E. Belowich, C. Valente, R. A. Smaldone, D. C. Friedman, J. Thiel, L. Cronin and J. F. Stoddart, J. Am. Chem. Soc., 2012, 134, 5243; (b) A. J. Avestro, D. M. Gardner, N. A. Vermeulen, E. A. Wilson, S. T. Schneebeli, A. C. Whalley, M. E. Belowich, R. Carmieli, M. R. Wasielewski and J. F. Stoddart, Angew. Chem., Int. Ed., 2014, 53, 4442 .

19 (a) M. B. Nielsen, C. Lomholt and J. Becher, Chem. Soc. Rev., 2000, 29, 153; (b) C. P. Collier, G. Mattersteig, E. W. Wong, Y. Luo, K. Beverly, J. Sampaio, F. M. Raymo, J. F. Stoddart and J. R. Heath, Science, 2000, 289, 1172; (c) J. L. Segura and N. Martín, Angew. Chem., Int. Ed., 2001, 40, 1372; (d) J. O. Jeppesen, M. B. Nielsen and J. Becher, Chem. Rev., 2004, 104, 5115; (e) D. Canevet, M. Sallé, G. Zhang, D. Zhang and D. Zhu, Chem. Commun., 2009, 2245 .

20 (a) D. L. Coffen and P. E. Garrett, Tetrahedron Lett., 1969, 10, 2043; (b) S. Hünig, G. Kießlich, H. Quast and D. Scheutzow, Liebigs Ann. Chem., 1973, 310.

21 Q. Zhang, D. H. Qu, Q. C. Wang and H. Tian, Angew. Chem., Int. Ed., 2015, 54, 15789.

22 S. V. Rosokha and J. K. Kochi, J. Am. Chem. Soc., 2007, 129, 828.

23 V. Khodorkovsky, L. Shapiro, P. Krief, A. Shames, G. Mabon, A. Gorgues and M. Giffard, Chem. Commun., 2001, 2736.

24 (a) A. Y. Ziganshina, Y. H. Ko, W. S. Jeon and K. Kim, Chem. Commun., 2004, 806; (b) M. Yoshizawa, K. Kumazawa and M. Fujita, J. Am. Chem. Soc., 2005, 127, 13456.

25 P. T. Chiang, N. C. Chen, C. C. Lai and S. H. Chiu, Chem. Eur. J., 2008, 14, 6546.

26 I. Aprahamian, J. C. Olsen, A. Trabolsi and J. F. Stoddart, Chem. - Eur. J., 2008, 14, 3889.

27 J. M. Spruell, A. Coskun, D. C. Friedman, R. S. Forgan, A. A. Sarjeant, A. Trabolsi, A. C. Fahrenbach, G. Barin, W. F. Paxton, S. K. Dey, M. A. Olson, D. Benitez, E. Tkatchouk, M. T. Colvin, R. Carmielli, S. T. Caldwell, G. M. Rosair, S. G. Hewage, F. Duclairoir, J. L. Seymour, A. M. Slawin, W. A. Goddard III, M. R. Wasielewski, G. Cooke and J. F. Stoddart, Nat. Chem., 2010, 2, 870.

28 (a) H. V. Schröder, H. Hupatz, A. J. Achazi, S. Sobottka, B. Sarkar, B. Paulus and C. A. Schalley, Chem. - Eur. J., 2017, 23, 2960; (b) H. V. Schröder, S. Sobottka, M. Nössler, H. Hupatz, M. Gaedke, B. Sarkar and C. A. Schalley, Chem. Sci., 2017, 8, 6300; (c) H. V. Schröder, J. M. Wollschläger and C. A. Schalley, Chem. Commun., 2017, 53, 9218.

29 H. Nagai, Y. Suzaki and K. Osakada, Eur. J. Inorg. Chem., 2014, 2014, 4376.
30 H. V. Schröder, F. Witte, M. Gaedke, S. Sobottka, L. Suntrup, H. Hupatz, A. Valkonen, B. Paulus, K. Rissanen, B. Sarkar and C. A. Schalley, Org. Biomol. Chem., 2018, 16, 2741.

31 T. Matsumura, F. Ishiwari, Y. Koyama and T. Takata, Org. Lett., 2010, 12, 3828.

32 (a) C. A. Hunter and J. K. M. Sanders, J. Am. Chem. Soc., 1990, 112, 5525; (b) C. R. Martinez and B. L. Iverson, Chem. Sci., 2012, 3, 2191.

33 (a) D. L. Sun, S. V. Rosokha, S. V. Lindeman and J. K. Kochi, J. Am. Chem. Soc., 2003, 125, 15950; (b) V. A. Azov, R. Gómez and J. Stelten, Tetrahedron, 2008, 64, 1909; (c) M. Hasegawa, K. Daigoku, K. Hashimoto, H. Nishikawa and M. Iyoda, Bull. Chem. Soc. Jpn., 2012, 85, 51.

34 (a) K. D. Demadis, C. M. Hartshorn and T. J. Meyer, Chem. Rev., 2001, 101, 2655; (b) M. B. Robin and P. Day, Adv. Inorg. Chem. Radiochem., 1968, 10, 247.

35 (a) Y. Wang, S. Mendoza and A. E. Kaifer, Inorg. Chem., 1998, 37, 317; (b) W. S. Jeon, K. Moon, S. H. Park, H. Chun, Y. H. Ko, J. Y. Lee, E. S. Lee, S. Samal, N. Selvapalam, M. V. Rekharsky, V. Sindelar, D. Sobransingh, Y. Inoue, A. E. Kaifer and K. Kim, J. Am. Chem. Soc., 2005, 127, 12984.

36 J. M. Lu, S. V. Rosokha and J. K. Kochi, J. Am. Chem. Soc., 2003, 125, 12161.

37 A. Coskun, J. M. Spruell, G. Barin, A. C. Fahrenbach, R. S. Forgan, M. T. Colvin, R. Carmieli, D. Benitez, E. Tkatchouk, D. C. Friedman, A. A. Sarjeant, M. R. Wasielewski, W. A. Goddard III and J. F. Stoddart, J. Am. Chem. Soc., 2011, 133, 4538.

38 (a) F. A. Walker, H. Boi Hanh, W. R. Scheidt and S. R. Osvath, J. Am. Chem. Soc., 1986, 108, 5288; (b) C. Gouverd, F. Biaso, L. Cataldo, T. Berclaz, M. Geoffroy, E. Levillain, N. Avarvari, M. Fourmigué, F. X. Sauvage and C. Wartelle, Phys. Chem. Chem. Phys., 2005, 7, 85.

39 (a) G. Barin, A. Coskun, D. C. Friedman, M. A. Olson, M. T. Colvin, R. Carmielli, S. K. Dey, O. A. Bozdemir, M. R. Wasielewski and J. F. Stoddart, Chem. - Eur. J., 2011, 17, 213; (b) M. Hasegawa, J.-I. Takano, H. Enozawa, Y. Kuwatani and M. Iyoda, Tetrahedron Lett., 2004, 45, 4109. 40 (a) M. Iyoda, K. Hara, Y. Kuwatani and S. Nagase, Org. Lett., 2000, 2, 2217; (b) M. Iyoda, M. Hasegawa and Y. Miyake, Chem. Rev., 2004, 104, 5085; (c) M. Hasegawa, K. Nakamura, S. Tokunaga, Y. Baba, R. Shiba, T. Shirahata, Y. Mazaki and Y. Misaki, Chem. - Eur. J., 2016, 22, 10090.

41 (a) M. Lohse, K. Nowosinski, N. L. Traulsen, A. J. Achazi, L. K. S. von Krbek, B. Paulus, C. A. Schalley and S. Hecht, Chem. Commun., 2015, 51, 9777; (b) K. Nowosinski, L. K. S. von Krbek, N. L. Traulsen and C. A. Schalley, Org. Lett., 2015, 17, 5076; (c) L. K. S. von Krbek, A. J. Achazi, S. Schoder, M. Gaedke, T. Biberger, B. Paulus and C. A. Schalley, Chem. - Eur. J., 2017, 23, 2877.

42 E. Hanozin, B. Mignolet, D. Morsa, D. Sluysmans, A. S. Duwez, J. F. Stoddart, F. Remacle and E. De Pauw, ACS Nano, 2017, 11, 10253. 
43 (a) M. Capdevila-Cortada and J. J. Novoa, Chem. - Eur. J., 2012, 18, 5335; (b) M. Fumanal, M. Capdevila-Cortada and J. J. Novoa, Phys. Chem. Chem. Phys., 2017, 19, 3807.

44 (a) J. Dale and P. O. Kristiansen, J. Chem. Soc. D, 1971, 670; (b) D. K. Frantz, A. Linden, K. K. Baldridge and J. S. Siegel,
J. Am. Chem. Soc., 2012, 134, 1528; (c) C. I. Ratcliffe, J. A. Ripmeester, G. W. Buchanan and J. K. Denike, J. Am. Chem. Soc., 1992, 114, 3294; (d) V. N. Vukotic, K. J. Harris, K. Zhu, R. W. Schurko and S. J. Loeb, Nat. Chem., 2012, 4, 456. 